\title{
Tumour suppressor genes
}

\author{
Loss of these genes may cause cancer
}

The neoplastic change in normal cells depends on the derangement of genetic functions controlling growth and differentiation. Mutations within normal genes may produce altered proteins that give cells a continuous signal to proliferate-thus blocking specific steps of cell differentiation. Such altered genes are called oncogenes. ' In addition, changes in the degree of expression of normal genes-induced by mutation, translocation, or insertion of virus-may lead to the inappropriate production of a protein such that cell maturation is prevented. For example, in Burkitt's lymphoma the myc gene is translocated into an active immunoglobulin locus, producing permanent expression of a protein that may play a part in DNA replication. Such changes seem to be "dominantly acting" as the mutation is enough on its own to drive the cell towards malignancy. Now we are learning about a second class of mutations in which loss of a gene is important for malignant transformation.

Cytogenetic analysis has shown that many human tumours exhibit a loss of genetic material at specific chromosomal loci. These losses are specific for a given tumour type but differ among tumours. The absence of functional genes at these loci is required to permit tumour development; moreover, both alleles (copies of homologous chromosomes) must be lost.

These genes have been named "tumour suppressor genes" or "antioncogenes," and the mutations that cause cancer may be regarded as "recessive" as both copies of the gene must be defective to promote neoplastic development. The discovery of the tumour suppressor genes promises insight into the processes leading to normal differentiation and the way in which they may be disrupted during cellular transformation. Clinically it provides a new opportunity to assess cancer susceptibility within families and to screen defined patients for certain types of cancer when early intervention may be critical. Understanding the function of these genes may also lead to new treatments.

\section{Genetics of cancer}

That cancer may be genetically determined has long been recognised.' As it became clear that some types of cancer cluster in families Knudson suggested that subjects heterozygous for a recessive mutation will develop the cancer when the mutation is made homozygous by a subsequent mutation at the remaining intact allele. ${ }^{3}$ In 1973 Comings proposed that genes active at embryogenesis (transforming genes) are suppressed at differentiation by dominant "suppressor" genes. ${ }^{+}$Within any compartment of stem cells cycling cells will differentiate only in response to a particular signal; one class of genes (the proto-oncogenes) may be viewed as the genes required to keep the cells cycling, and the second class (the tumour suppressors) may be seen as those genes that override the proliferative signals and allow the cell to differentiate. The loss of both copies of any of these suppressor genes would allow continued expression of the proliferative genespermitting the first stages of malignant transformation.

These ideas are supported $\because$ the finding that some of the familial cancer syndromes are inked to inheritance of a loss of

\section{Key points}

- The loss of tumour suppressor genes may lead to cancer

- The normal function of the suppressor genes may be to override proliferative signals and allow cell differentiation

- In familial cancers one copy of the suppressor gene may be lost from the chromosome and a second by mutation

- In sporadic cancers both copies of the same suppressor genes may be lost by mutation

- An understanding of tumour suppressor genes may lead to new methods of screening and even treatment

a defined chromosomal locus at one allele. This mutation predisposes the person to the cancer, but for the disease to emerge a second mutation is required somatically at the unaffected allele in the cell(s) that eventually transform. In cancers with sporadic as well as familial forms the same chromosomal locus is affected in some cases, but both alleles are inactivated somatically. The differences in the patients' ages and in the features of the cancers at presentation support such a model.

There is a rapidly growing list of tumours that are associated with homozygous loss of specific chromosomal loci (table) ${ }^{5-7}$ But until genetic linkage studies have been carried out for each type we do not know which losses represent germline alleles important in contributing a genetic predisposition to the cancer.

Much laboratory research has also implied the existence of genes capable of suppressing malignancy. For example, the fusion of a normal cell with a malignant cell produces a hybrid in which the tumorigenic phenotype is usually suppressed and the differentiation programme of the normal cell may be imposed. ${ }^{8}$ Subsequent chromosomal loss from the hybrid may lead to the reappearance of tumorigenicity. The loss of specific chromosomal loci may be linked to the reappearance of tumorigenicity - suggesting that tumour suppressive information resides at these loci. These and other experiments, whereby tumour cells may revert to the non-tumorigenic phenotype after transfer of specific pieces of DNA, allow the identification of the genes mediating cellular transformation.

\section{Model of retinoblastoma}

It was Knudson's statistical analysis of the two forms of the childhood cancer retinoblastoma that gave rise to the notion of "antioncogenes." Retinoblastoma occurs in about one in 14000 live births, existing in two forms, familial and sporadic, which differ in the extent of tumour formation and in the age when the patient presents. In both forms a locus on the long arm of chromosome 13 is disrupted at both alleles.

In the familial form deletion of the locus has been observed cytogenetically (in a few cases) on one copy of chromosome 13 in the germline. This inherited defect thus predisposes the carrier to retinoblastoma. During development of the retinal cell it is assumed that a mutation causes loss of the second 


\begin{tabular}{lcl}
\hline & $\begin{array}{c}\text { Principal locus } \\
\text { of repeatedly } \\
\text { observed loss of } \\
\text { allele in tumour }\end{array}$ \\
\hline Tumour type & $13 \mathrm{q}$ & \\
\hline Retinoblastoma & $13 \mathrm{q}$ & ॠTumours for which the \\
Osteosarcoma & $13 \mathrm{q}$ & locus shown has been \\
Ductal breast carcinoma & $11 \mathrm{p}$ & associated with an inherited \\
Wilms's tumour & $11 \mathrm{p}$ & predisposition. Recent \\
Rhabdomyosarcoma & $11 \mathrm{p}$ & reports show that in some \\
Hepatoblastoma & $5 \mathrm{q}$ & families the familial \\
Colon carcinoma (familial polyposis) & $1 \mathrm{p}$ & predisposition to Wilms's \\
Insulinoma & $3 \mathrm{p}$ & tumour may not map to \\
Renal carcinoma & 22 & $11 \mathrm{p}$. $^{*}$ \\
Meningioma & $3 \mathrm{p}$ & \\
Small cell lung carcinoma & 10 & \\
Medullary thyroid carcinoma & & \\
\hline
\end{tabular}

copy of the retinoblastoma gene. (This event is often observable as a large scale disruption such as loss of a chromosome.) Hence the protein specified by the gene is not produced and differentiation cannot occur. Clinically, familial retinoblastoma presents with bilateral and multifocal tumoursconsistent with the notion that all retinal cells have inherited the first mutation and that the second event has occurred in several cells. Such cases usually appear between the ages of 1 and 3 years.

In sporadic retinoblastoma a single affected eye has just a single tumour focus and the disease appears later in childhood. In this case it is envisaged that both copies of the locus on chromosome 13 are inherited intact but that two separate somatic mutations occur at each allele of the retinoblastoma gene-permitting tumour development. The need for two independent events to occur at separate loci accounts both for the later appearance of the tumour and for its formation at a single focus. Retinoblastoma is rarely diagnosed beyond the age of 7 , implying that development of retinal cells is complete by then and that any subsequent alterations in the retinoblastoma gene do not affect the fate of the cell.

The retinoblastoma gene has recently been cloned in Weinberg's laboratory. ${ }^{10}$ It seems to encode a protein that binds other proteins in the nucleus-perhaps to form a complex that participates in regulating cellular differentiation. Intriguingly, it binds to the proteins of several DNA tumour viruses, $" 12$ suggesting that some oncogenic viruses may cause cancers in part by sequestrating the products of tumour suppressor genes, thereby blocking cell differentiation.

Osteosarcoma may also be associated with the double loss of the retinoblastoma gene as patients rescued from familial retinoblastoma have a greatly increased risk of developing osteosarcoma. Recently, structural alterations of the retinoblastoma gene have been shown in some cases of melanoma, small cell lung carcinoma, ${ }^{13}$ and breast cancer. ${ }^{1+}$ These findings and the apparently widespread expression of the gene in many tissues suggest that tumour suppressor genes may act pleiotropically in the differentiation programmes of several cell types.

\section{Theoretical or practical gains?}

Loss of heterozygosity at tumour suppressor loci is clearly important in the genesis of some rare familial cancers, but these new findings may also be important in common cancers. Loss of alleles at specific loci has been observed in several common cancers - including those of the lung ${ }^{15}$ and the breast. ${ }^{16}$ But it is still far from certain that loss of a single allele at these loci in the germline will lead to an increased risk of developing cancer. Many cytogenetic abnormalities may be present in a malignant cell, and the affected loci may be important in either initiation or progression of tumours.

Techniques exist whereby families with a high incidence of a cancer may be studied to ascertain which genetic loci cosegregate with the cancer. If identifiable genetic changes can be associated with common cancers then such DNA technology might find widespread use in screening for specific cancers. The screening of members of a family with a known predisposition to a specific cancer might highlight those at high risk of developing the "second hit" mutation after having already inherited the first genetic lesion. Such knowledge would permit early detection, leading possibly to more effective treatment. Retinoblastoma itself is readily managed by an early operation. In addition, parents may be told the risk to any future child of developing the cancer. Prenatal risk assessment of such cancers would also become available, but it is important to remember that, unlike monogenic disorders such as the absence of a single globin gene, a tumour represents the summation of several genetic lesions. Therefore inheritance by the fetus of a predisposition to a cancer (which may be treated successfully) will raise ethically complex issues regarding the termination of pregnancy. Finally, identifying and cloning suppressor genes may permit population screening programmes for some cancers.

Whether these findings will give rise to new approaches to intervention is speculative. It may eventually prove possible to replace a missing gene, which might be more successful than current attempts at counteracting the action of oncogenes. ${ }^{17}$ But the techniques are still remote. After years of research into oncogenes little has emerged that is relevant to managing patients. The challenges presented by tumour suppressors are different and may provide new opportunities to relate the theory of the aberrant behaviour of a cancer cell to its correction.

I thank Dr Steven Russell, Dr Jonathan Weber, and Professor Robin Weiss for their help and critical advice in preparing this manuscript. I am supported by a grant from the Leukaemia Research Fund.

RICHARD VILE

Research Scientist,

Chester Beatty Laboratories,

Institute of Cancer Research,

London SW3 6JB

1 Weber J, MeClure M. Oncogenes and cancer. Br.Med f 1987:294:12+6-8.

2 Broca PP. Traite des tumeurs. Paris: Asselin, 1866.

3 Knudson AG. Mutation and cancer: statistical studv of retinoblastoma. Proc Natl diad SCi USA $1971 ; 68: 820-3$.

+ Comings DE. A general theory of carcinogenesis. Proc Natl Acad Sci LSA 1973;70:3324-8.

5 Ponder B. Gene losses in human tumours. Nature 1988:335:400-2.

6 Grundy P, Koufos A, Morgan K, Lee F, Meadows A, Cavenee W. Familial predisposition to Wilms' tumour does not map to the short arm of chromosome 11. Nuture 1988;336:374-6.

7 Huff V, Compton DA. Chao L.Y, Strong L, Geiser C, Saunders G. Lack of linkage of familial W'ilms' tumour to chromosomal band 11-13. Nature 1988;336:377-8.

8 Harris $\mathrm{H}$. The analysis of malignancy by cell fusion: the position in 1988. Cancer Res 1988;48: $3302-6$.

9 Weissman BE, Saxon PJ, Pasquale SR, Jones GR, (jeiser AG, Stanbridge EJ. Introduction of a normal human chromosome 11 into a Wilms' tumor cell line controls its tumorigenic expression. Sicience 1987:236:175-80.

10 Friend SH, Bernards R, Rogelj S, ct al. A human DNA segment with properties of the gene that predisposes to retinoblastoma and osteosarcoma. Nature 1986;323:6+3-6.

11 Whyte P, Buchkovich KJ, Horowitz JM, et al. Association between an oncogene and an antioncogene: the adenowirus ElA proteins bind to the retinoblastoma gene product. Nature oncogene: the aden

12 DeCaprio JA, Ludlow JW, Figge I, et ul. SV 40 large tumour antigen forms a specific complex with the product of the retinoblastoma susceptibility gene. Cell 1988;54:275-83.

13 Harbour JW, Shinn-Liang L. Whang-Peng J, Gazdar AF, Minna JD, Kaye FJ. Abnormalities in structure and expression of the human retinoblastoma gene in SCLC. Science 1988;241:353-6.

$1+$ T'Ang A, Varley JM, Chakraborty S. Murphree AL, Fung Y-K T. Structural rearrangement of the retinoblastoma gene in human breast carcinoma. Sicience 1988;242:263-6.

15 Yokato J, Wada M. Shimostao Y, Terada M. Sugimura T. Loss of heterozygosity on chromosomes 3,13 and 17 in small cell carcinoma and on chromosome 3 in adenocarcinoma of the lung. Proc Nall Acad Sci USA 1987;84:9252-6.

16 Mackay J, Steel CM, Elder PA, Forrest P, Evans HJ. Allele loss on short arm of chromosome 17 in breast cancers. Lancet 1988;ii:1384-5.

17 Huang SH-J, Yee J-K, Shew J-Y, et al. Suppression of the neoplastic phenotype by replacement of the RB gene in human cancer cells. Science 1988;242:1563-6.

\section{Further reading}

Friend SH, Drvia TP, Weinberg RA. Oncogenes and tumour-suppressing genes. N Eingl f . Hed 1988;318:618-41.

Weinberg RA. Finding the anti-oncogene. Scientific American 1988:259:34-41. 